\title{
Analyzing Urban Growth Pattern and Driving Factors Using Remote Sensing and GIS: A Case Study of Banepa Municipality, Nepal
}

\author{
Rabina Twayana, Sijan Bhandari, Reshma Shrestha \\ rabinatwayana123@gmail.com, sijanbhandari12@gmail.com, reshma@ku.edu.np
}

\section{KEYWORDS}

Urban Growth, Driving Factors, Analytical Hierarchy Process (AHP)

\begin{abstract}
Nepal is considered one of the rapidly urbanizing countries in south Asia. Most of the urbanization is dominated in large and medium cities i.e., metropolitan, submetropolitan, and municipalities. Remote Sensing and Geographic Information System (GIS) technologies in the sector of urban land governance are growing day by day due to their capability of mapping, analyzing, detecting changes, etc. The main aim of this paper is to analyze the urban growth pattern in Banepa Municipality during three decades (1992-2020) using freely available Landsat imageries and explore driving factors for change in the urban landscape using the AHP model. The Banepa municipality is taken as a study area as it is one of the growing urban municipalities in the context of Nepal. The supervised image classification was applied to classify the acquired satellite image data. The generated results from this study illustrate that urbanization is gradually increasing from 1992 to 2012 while, majority of the urban expansion happened during 2012-2020, and it is still growing rapidly along the major roads in a concentric pattern. This study also demonstrates the responsible driving factors for continuous urban growth during the study period. Analytical Hierarchy Process (AHP) was adopted to analyze the impact of drivers which reveals that, Internal migration (57\%) is major drivers for change in urban dynamics whereas, commercialization (25\%), population density (16\%), and real estate business (5\%) are other respective drivers for alteration of urban land inside the municipality. To prevent rapid urbanization in this municipality, the concerned authorities must take initiative for proper land use planning and its implementation on time. Recently, Nepal Government has endorsed Land Use Act 2019 for preventing the conversion of agricultural land into haphazard urban growth.
\end{abstract}

\section{INTRODUCTION}

\subsection{Background}

Urban growth is defined as the physical and functional changes in the urban landscape
(Thapa \& Murayama, 2010). Nepal is considered one of the rapidly urbanizing countries in south Asia (Devkota, 2018). According to Muzzini \& Aparicio (2013), the average urban population growth rate 
of Nepal is about $6 \%$ per annum since the 1970s. Most of the urbanization is dominated in large cities i.e., metropolitan and sub-metropolitan cities, and medium cities i.e. municipalities (Bakrania, 2015). Various factors are responsible for the rapid urbanization in Nepal. According to Thapa and Murayama (2010), physical topography, services accessibility, economic opportunities, land market, bombing in real estate market, population growth, existing plans and policies related to the urban governance, etc. are the major driving factors for urban landscape change in Nepal. Growing urbanization in Nepal has also affected the social, economic, environmental, cultural aspects of various regions of Nepal (Ishtiaque, Shrestha, \& Chhetri, 2017). In addition to this, growing urbanization has caused various problems in urban regions such as; overcrowding, housing problems, unemployment, development of slums, water and sanitation, poor health and spread of diseases, traffic congestion, urban crime, etc. (Rinkesh, 2019). Thus, proper urban planning and implementation approaches/ technologies must be adopted to eradicate the negative impacts of urbanization.

With the development of advanced geospatial technologies, it has fetched huge applications in the domain of Urban land governance. The use of Remote Sensing and Geographic Information System (GIS) technologies in the sector of urban land governance is growing day by day due to its capability of mapping, analyzing, detecting changes, etc. Using the spatial multi-temporal remotely sensed satellite images, provides a unique perspective to analyze how urban cities are evolving ( Stefanova \& Ramseyc, 2001). In addition to this, remote sensing is specifically used for classifying the various urban regions such as; agriculture, built-up, barren, water bodies, etc. Furthermore, GIS is specifically used for data spatial and non-spatial data management, mapping, surveying, etc.
The study on urban growth patterns is important to understand to control hazard and unplanned growth. Using the latest geospatial technologies helps in analyzing the urban dynamics pattern spatially and temporally which supports the formulation and implementation of urban planning model to achieve sustainable urban land governance.

\subsection{Objectives}

The main objective of this paper is to analyze the urban growth pattern in Banepa Municipality from the past three decades (1992-2020) using Landsat imageries and explore driving factors for change in the urban landscape using the AHP model.

\subsection{Study Area}

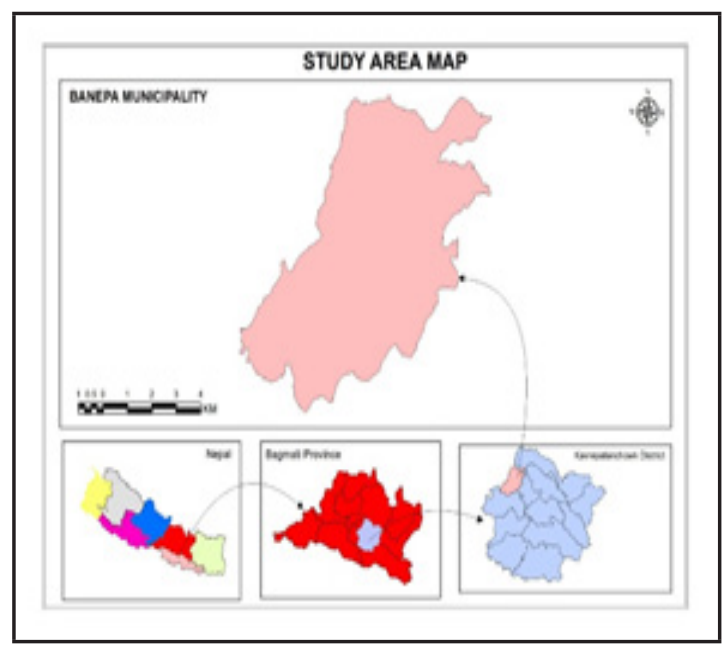

Figure 1: Study Area Map

The Banepa municipality is considered as one of the growing urban municipality in the context of Nepal due to commercial hub, accessibility of highways and urban roads, the attraction of tourists to religious and historical sites, hospital services, educational facilities, etc. It is located at $27^{\circ} 38^{\prime} \mathrm{N}$ and $85^{\circ} 31^{\prime} \mathrm{E}$ and lies at $1500 \mathrm{~m}$ above the sea level. It has an area of approximately $55 \mathrm{~km} 2$ which consists of 14 administrative wards (Ministry of Federal Affairs and General Administration, 2017). According to the Central Bureau of Statistics, the population of this municipality was 55 , 
628 having a population density of $10,000 /$ $\mathrm{km} 2$. based on the 2011 census.

\subsection{Data Used}

Table 1: Characteristics of Acquired Image Data

\begin{tabular}{|c|c|c|c|c|}
\hline Data Type & $\begin{array}{c}\text { Acquisition } \\
\text { Date }\end{array}$ & Band & Resolution & Source \\
\cline { 1 - 4 } $\begin{array}{c}\text { LandSat5 } \\
\text { TM }\end{array}$ & 29 Mar 1992 & Multispectral & $30 \mathrm{~m}$ & \\
\cline { 1 - 4 } $\begin{array}{c}\text { LandSat7 } \\
\text { TM }\end{array}$ & 02 Apr 2002 & Multispectral & $30 \mathrm{~m}$ & \multirow{2}{*}{ USGS } \\
\cline { 1 - 4 } $\begin{array}{c}\text { LandSat7 } \\
\text { ETM+ }\end{array}$ & 12 Apr 2012 & Multispectral & $30 \mathrm{~m}$ & \\
\cline { 1 - 3 } $\begin{array}{c}\text { LandSat8 } \\
\text { OLI }\end{array}$ & 4 Apr 2020 & Multispectral & $30 \mathrm{~m}$ & \\
\hline
\end{tabular}

Table 1 describes the characteristics of acquired satellite imagery data from the USGS website. The main reason for choosing this acquisition date is due to the availability of the google earth imageries $(2002,2012,2020)$ and Topo-Sheets data (1992) of the study area to perform an accuracy assessment of the classified images.

\section{METHODOLOGY}

\subsection{Satellite Images Acquisition and Pre- processing:}

Initially, freely available satellite images were acquired from the United States of Geological Survey (USGS) website of the respective year; 1992,2002,2012, and 2020. Then, consecutive operations i.e., Radiometric calibration, FLASH atmospheric correction, and geometric correction were carried out in ENVI software. In radiometric calibration, DN's of acquired satellite imageries are converted into radiance and then obtained radiance values are again converted into Top of Atmosphere (TOA).

FLASH is the atmospheric correction method that corrects wavelength in the visible through near-infrared and short-wave infrared regions to decrease the influence of scattering and absorption of an atmospheric molecule on object reflectance. FLASH was selected over other methods since it considers different atmospheric parameters such as visibility, aerosol types, zenith angles, azimuthal angles, etc. and can reduce atmospheric effects more effectively (Schläpfer et al., 2018). According to (Felde et al., 2003), mathematically this model can be represented as;

$$
L=\left(\frac{A_{\rho}}{1-\rho_{e} S}\right)+\left(\frac{B_{\rho}}{1-\rho_{e} S}\right)
$$

where, $\mathrm{r}=$ pixel surface reflectance

$P_{e}=$ average surface reflectance for the pixel and surrounding region

$\mathrm{S}=$ spherical albedo of the atmosphere

$L_{a}=$ radiance backscattered by the atmosphere

$\mathrm{A}$ and $\mathrm{B}=$ coefficients that depend on the atmospheric and geometric conditions but not a surface.

The topography of the selected study area is very undulating which may result in geometrical distortion of acquired satellite images. Thus, to carry out change detection and multi-temporal analysis the acquired satellite imageries need to co-registered with each other. Using the image registration module and topographic map sheets (1:25000) published by Survey Department, Nepal geometric distortion was reduced sequentially.

\subsection{Image Classification}

Supervised Image classification with Maximum Likelihood Classifier (MLC), available in ENVI software was carried out to perform image classification. Initially, the image was planned to be classified into four land cover categories i.e., Built-up, Barren, Agriculture, and Forest land. To perform a maximum likelihood method classifier sufficient amount of training data should be available in the form of ground-referenced data for various land cover types (Karna, et al.). In this study minimum of 30 samples for each category were extracted to perform the image classification. 


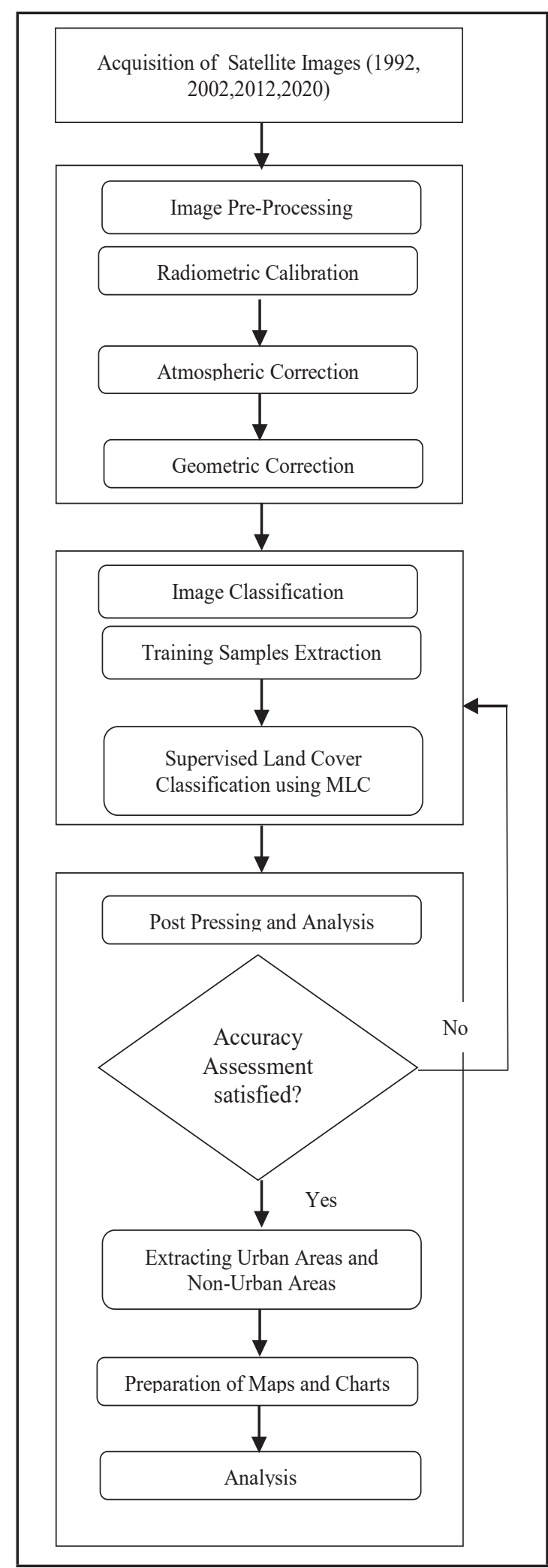

Figure 2: Methodological Flowchart

\subsection{Post-processing and Analysis}

Ground truth samples were collected from Google Earth Pro for year 2002,2012 and 2020 and samples were collected from georeferenced topo sheets for the year 1992 since google earth imagery were not found in this year. The accuracy assessment of prepared land cover maps was done via Confusion Matrix using Ground Truth ROIs under the post processing of ENVI. Minimum 30 samples were collected for each land cover class and tested over the classified image. 84.35\%, 83.70\%, 85.71\% and $86.82 \%$ of overall accuracy and 0.788 , $0.778,0.806$ and 0.821 kappa statistics were obtained for year 1992,2002,2012 and 2020 respectively.

After obtaining the desirable accuracy of image classification, they were further classified into binary classification (Urban and Non-Urban areas). The main aim of binary classification is to precisely distinguish the urban and nonurban lands inside the study area. The binary classification was carried out by merging agriculture, forest, and barren categories as non-urban areas and remained builtup areas as it is.

According to (As-syakur et al., 2012), builtup and barren land has a similar reflectance value in satellite images thus, there is a high probability for misclassification which ultimately affects the overall results. In addition to this, agriculture and forest are highly dominant in the study area due to which the urban areas would be suppressed during image classification. Thus, to minimize suppression of urban areas and the misclassification, initially, images were classified into four categories and further in binary classification.

At last, respective binary maps along with necessary charts and graphs were prepared to disseminate and carrying out for further analysis. 


\subsection{Analyzing Impacts of Driving Factors Using AHP Model}

To analyze the responsible driving factors for change in urban growth patterns, at first desk study was performed to identify, select and define the major drivers as per necessity. Then using the framework in figure 3 analysis was proceed further. At first, subjective judgment and pair wise matrix of the selected drivers were prepared based on scale range as illustrated in the table 2 developed by (Saaty, 1986).

Internal Migration(D1), population density (D2), Commercialization(D3), Real estate business (D4) were four drivers used in this study. To check the consistency of the subjective judgment, the consistency ratio (CR) needs to be evaluated significantly.

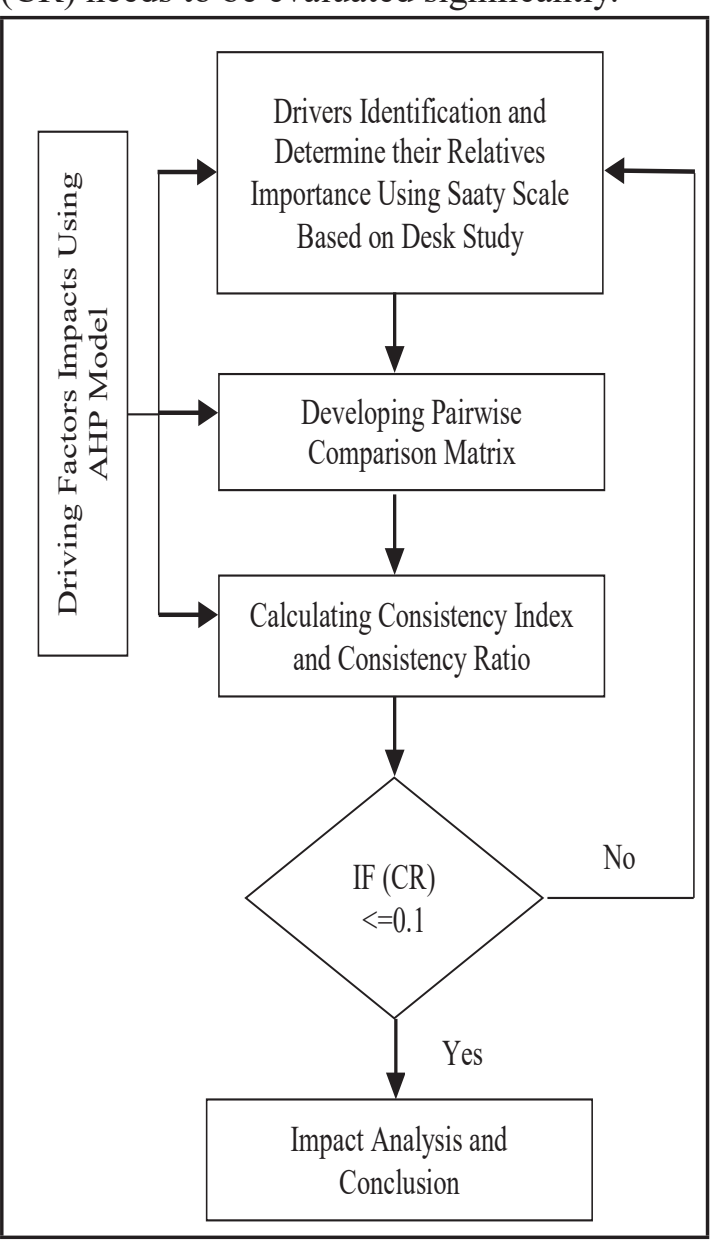

Figure 3: AHP Framework
Table 2: Saatty rating scale

\begin{tabular}{|c|c|}
\hline \multicolumn{2}{|c|}{ Saatty Rating Scale } \\
\hline 1 & Equal Importance \\
\hline 3 & Moderate Importance \\
\hline 5 & Strong Importance \\
\hline 7 & Very Strong Importance \\
\hline 9 & Extreme Importance \\
\hline $2,4,6,8$ & Intermediate Importance \\
\hline $1 / 3,1 / 5,1 / 7,1 / 9$ & $\begin{array}{c}\text { Values for inverse } \\
\text { comparison }\end{array}$ \\
\hline
\end{tabular}

For evaluating the CR, firstly; the sum of a column of each driver was calculated using the pairwise matrix as illustrated in table3.

Table 3: Pairwise matrix

\begin{tabular}{|l|l|l|l|}
\hline D1 & D2 & D3 & D4 \\
\hline 1 & 5 & 4 & 7 \\
\hline 0.200 & 1 & 3 & 6 \\
\hline 0.250 & 0.333 & 1 & 5 \\
\hline 0.143 & 0.167 & 0.200 & 1 \\
\hline $\mathbf{1 . 5 9 3}$ & $\mathbf{6 . 5 0 0}$ & $\mathbf{8 . 2 0 0}$ & $\mathbf{1 9}$ \\
\hline
\end{tabular}

Then, each element of the pairwise matrix was normalized by, dividing each element of the matrix with its respective column summation value. The individual normalized elements (D11 to D44) and weights of each driver are illustrated in table 4 . The weight of the driver is also referred to as the priority vector/normalized principal eigen vector. The weight of each driver was calculated using the following formula.

$$
\text { Weight } \frac{\text { Ssum of all row elements ofpairwisematrix }}{\text { numberofdrivers }}
$$

Accordingly, for calculating the principal eigenvalue, the weighted sum (A) of each driver were calculated which is illustrated in the table 5 . 
Table 4: calculation of priority vector

\begin{tabular}{|c|c|c|c|c|}
\hline D1 & D2 & D3 & D4 & $\begin{array}{c}\text { Priority } \\
\text { Vector } \\
\text { (P) }\end{array}$ \\
\hline 0.628 & 0.765 & 0.480 & 0.438 & 0.578 \\
\hline 0.126 & 0.153 & 0.360 & 0.375 & 0.253 \\
\hline 0.157 & 0.051 & 0.120 & 0.313 & 0.160 \\
\hline 0.090 & 0.026 & 0.024 & 0.063 & 0.050 \\
\hline
\end{tabular}

Table 5: Calculation of weighted sum

\begin{tabular}{|c|c|c|c|c|}
\hline $\begin{array}{c}\text { D1" } \\
\text { (D1*P) }\end{array}$ & $\begin{array}{c}\text { D2" } \\
\text { (D1*P) }\end{array}$ & $\begin{array}{c}\text { D3*" } \\
\text { (D1*P) }\end{array}$ & $\begin{array}{c}\text { D4\%" } \\
\text { (D1*P) }\end{array}$ & $\begin{array}{c}\text { A } \\
\text { (D1*P) }\end{array}$ \\
\hline 0.363 & 0.194 & 0.077 & 0.022 & 0.164 \\
\hline 0.073 & 0.039 & 0.058 & 0.019 & 0.047 \\
\hline 0.091 & 0.013 & 0.019 & 0.016 & 0.035 \\
\hline 0.052 & 0.006 & 0.004 & 0.003 & 0.016 \\
\hline
\end{tabular}

Furthermore, using the formula as mentioned below the principal eigen value ( $\lambda$ max) was calculated and obtained as 4.161.

$$
\lambda \max =\frac{\text { weighted } \sum \text { of each criteria }(A)}{\text { weight of each criteria (Priority Vector) }}
$$

After, determining the value of $\lambda \max$ Consistency Index (CI) was calculated using the mentioned below formula. The CI value was obtained as 0.054 .

$$
\mathrm{CI}=\frac{\lambda \max ^{-n}}{n-1}
$$

$\mathrm{n}=$ number of drivers used.

Finally, the CR value needs to be calculated to evaluate the consistency of the judgment. In this study, CI was obtained as 0.060 (acceptable) using the formula as mentioned below. According to Saaty (1986), the value of RI depends upon the number of drivers used, thus, $\mathrm{RI}=0.89$ for $\mathrm{n}=4$.

$$
\mathrm{CR}=\frac{C I(\text { Consistency Index })}{R I(\text { Random Consistency Index })}
$$

\section{RESULTS AND DISCUSSION}

\subsection{Urban Growth Pattern}

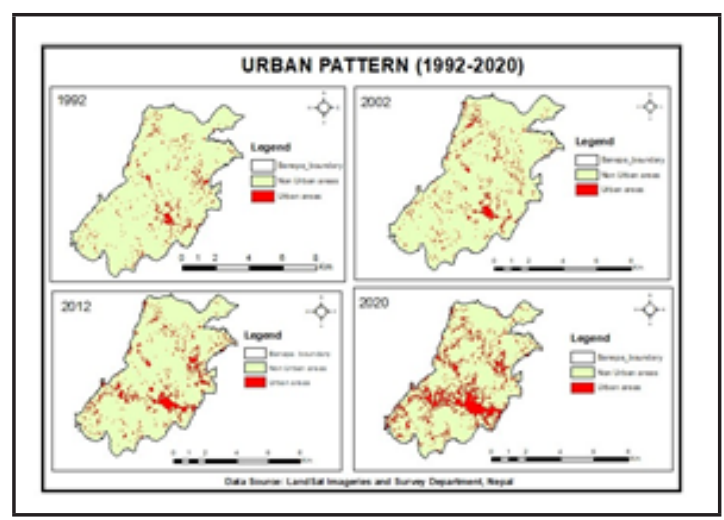

Figure 4: Map Showing Urban Pattern

Figure 4 demonstrates the urban growth pattern in each decade of the study area. It can be observed that the urbanization of the study area is gradually increasing since, 1992 to 2012 but has suddenly risen from 2012 to 2020. Highway and major roads network can be visualized in the given figure 4 which is extracted from toposheets of the year 1992 published by Survey Department, Nepal. It depicts that urbanization is growing rapidly along the roads in a concentric pattern till days. In addition to this, figure 4 also illustrates that the urbanization is mostly in the core area of the city (Banepa Bazzar) whereas scattered urban patterns can be depicted in upper regions from Araniko highway.

\subsection{Status of Urban Growth}

Table 6: Statistics of Land Cover

\begin{tabular}{|l|l|l|l|l|}
\hline \multicolumn{1}{|c|}{ Year } & \multicolumn{1}{c|}{$\mathbf{1 9 9 2}$} & \multicolumn{1}{c|}{$\mathbf{2 0 0 2}$} & $\mathbf{2 0 1 2}$ & $\mathbf{2 0 2 0}$ \\
\hline Urban areas (ha) & 273.96 & 361.98 & 558.54 & 983.16 \\
\hline Urban areas (\%) & 5.03 & 6.65 & 10.25 & 18.04 \\
\hline $\begin{array}{l}\text { Non-Urban areas } \\
\text { (ha) }\end{array}$ & 5173.20 & 5085.18 & 4888.62 & 983.16 \\
\hline $\begin{array}{l}\text { Non-Urban areas } \\
(\%)\end{array}$ & 94.97 & 93.35 & 89.74 & 81.95 \\
\hline
\end{tabular}

Figure 5 shows the trend of urban and nonurban areas from 1992 to 2020. It depicts that in 1992 total municipality was covered with 
273.96 ha of urban areas with $5.03 \%$ of its total land. Similarly, in 2002, 361.98 ha of land was covered with urban which occupies $6.65 \%$ of the total land of a municipality. Correspondingly, in 2012, urban areas slightly rose and cover an area of 558.54 ha which occupies $10.25 \%$ of the total land of Banepa. The municipality faced the highest urban growth in 2020 with an area of 983.16 ha occupying $18.04 \%$ of the total land.

The comparative analysis between built-up and non-built-up areas in each decadal interval can be depicted from the illustrated table 6 . It shows most of the land is covered with nonurban areas where only a few were covered with urban areas in the year 1992. Similarly, in 2002 and 2012 there was still dominancy of non-urban areas. Non-urban areas covered almost similar to that of 1992 with little diminutions. In 2020, large amount of nonurban areas was converted to urban areas which has ultimately raise urban growth of municipality in highest amount.

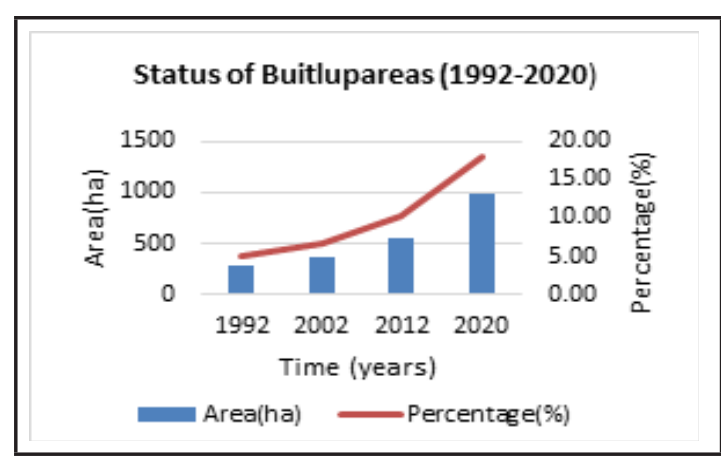

Figure 5: Graph Showing Status of Built-up Areas

\subsection{Change analysis of Urban areas}

Table 7: Statistics Showing Change in Urban Areas

\begin{tabular}{|l|c|c|c|c|c|c|}
\hline From-To & \multicolumn{2}{|c|}{ 1992-2002 } & \multicolumn{2}{|c|}{ 2002-2012 } & \multicolumn{2}{c|}{ 2012-2020 } \\
\hline Time period & \multicolumn{2}{|c|}{10} & \multicolumn{2}{c|}{10} & \multicolumn{2}{c|}{8} \\
\hline \multirow{3}{*}{ Change } & $\begin{array}{c}\text { Area } \\
\text { (ha) }\end{array}$ & $\%$ & $\begin{array}{c}\text { Area } \\
\text { (ha) }\end{array}$ & $\%$ & $\begin{array}{c}\text { Area } \\
\text { (ha) }\end{array}$ & $\%$ \\
\cline { 2 - 7 } & 88.02 & 1.62 & 196.56 & 3.60 & 424.62 & 7.79 \\
\hline $\begin{array}{l}\text { Annual Rate of } \\
\text { Change }\end{array}$ & 8.80 & 0.16 & 19.65 & 0.36 & 53.07 & 0.97 \\
\hline
\end{tabular}

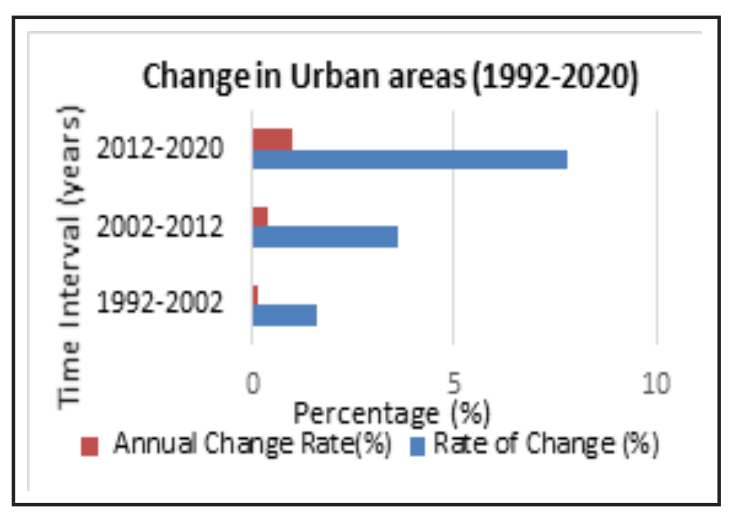

Figure 6: Graph Showing Rate of Change in Urban Areas

Table 7 illustrates the change in urban areas between each decade interval i.e., 1992-2002, 2002-2012, 2012-2020. It shows that between 1992 to 2002, urban areas grew at a rate of $0.16 \%$ (8.08 ha) per year, accumulating 1.62 $\%$ (88.02 ha) over this decade. Similarly, in the case of 2002-2012 urban areas were increased at a rate of $0.36 \%$ (19.65 ha) per year and cumulate an area of 196.56 ha (3.60 $\%$ ) between 2002-2012. Also, in the case of 2012-2020, the urban areas were continuously increased at a rate of $0.97 \%$ (53.07 ha) per annum which accumulate $7.79 \%$ (424.62 ha) of total land by end of this period.

\subsection{Driving factors}

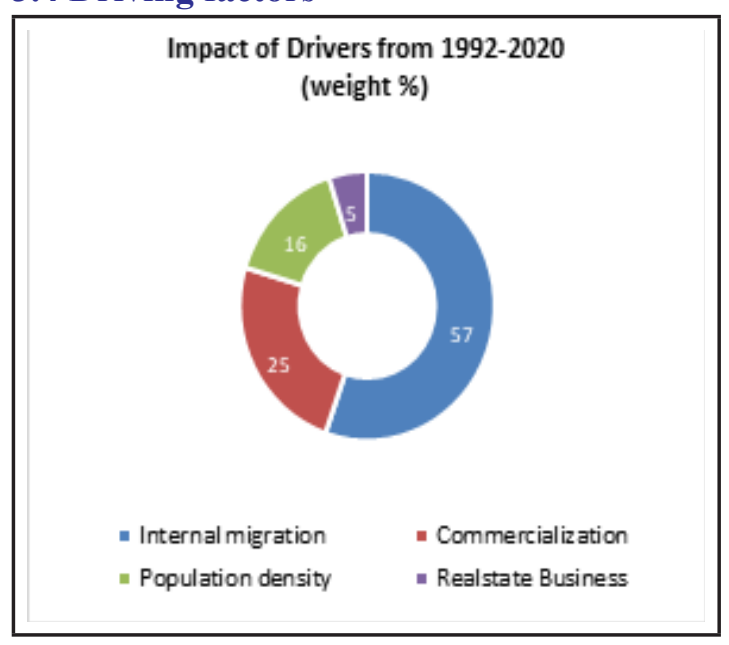

Figure 7: Chart Showing Impact of Driving Factors 
The selected driving factors; Internal Migration, Commercialization, Population density, and Real estate business, and their impact on urbanization was analyzed using the AHP model which is shown in figure 7. It confirms that internal migration with a weight of $57 \%$ is found to be a major responsible factor for urbanization inside the municipality. Based on Tiwari (2008), internal migration and urbanization are highly correlated to each other. The high flow rate of internal migration from a place to another place proportionally increases the urbanization of the drifted area. A document published by Thapa \& Murayama (2010), reveals that flow of migration from rural areas to urban areas since the 90's to the present date, is considered as one of the major drivers for rapid urbanization over various parts of Nepal. Accordingly, based on the data published by Kc (2004), internal migrant flow from rural areas to urban areas is continuously increasing in Kathmandu city and nearer urban cities of Nepal such as; bhaktapur, banepa, dhulikhel, etc. In the case of Banepa, individuals are migrated from rural areas of kavre district (Dohalghat, Roshi, Bethanchowk, Khanikhoa etc) for better physical infrastructure facilities, education and health facilities, employment opportunities, commercial business because, a major highway of our nation (Araniko Highway) passes through this municipality, a leading university (Kathmandu University) and wellrenowned hospital (Dhulikhel Hospital) are situated near to this municipality. In addition to this, it is also found that this municipality is a vital commercial hub of care district due to which people are also migrating in high flow rate from rural areas to core area (banepa bazzar) which has resulted the enormous urban growth across core area.

Commercialization with a weight $25 \%$ is found to be another responsible factor after internal migration for rapid urban changes of a municipality. According to Tiwari (2008) commercialization is highly interlinked to urbanization. It involves; transactions, modern marketing, and exchange methods which enormously give rise to the growth of urban cities.

Based on the information retrieved from the municipal official website; https:// banepamun. gov.np reveals most of the Newari communities are attracted to commercial business since the historical development of the city. Thus, most of the peoples are found to be engaged in a commercial business which has ultimately rise urbanization inside the city since 90 s to 2020 . Population density with a weight of $16 \%$ is found to be the third driver which is responsible for the urban growth inside the municipality. According to the Salas (1986), population dynamics and change in the urban landscape are positively correlated to each other which states that with an increase in population density urbanization will be ultimately increased in any specific region. Various studies were already accomplished to analyze the trend of population dynamics in urban areas and its impact on the urbanization of Nepal. A report published by (Nepal Urban Population 1960-2021, 2021), demonstrates a significant increase in the population throughout major cities of Nepal since 90s to 2020, with has increased in new settlements. Thus, being an urban city of Nepal since the late 90's banepa municipality is also experiencing an additional expansion of settlements from 90s to 2020 resulting in enormous urban growth

The real estate business has also impacted the urban dynamics of banepa municipality. The AHP model used in this study reveals it weighs $5 \%$, which is comparatively less than that of three drivers (Internal migration, Commercialization, Population density). Since 2000, the real estate business found to be introduced due to the high demand of the 
land for the construction of buildings, houses, apartments, etc mainly in various city areas of Nepal (Ishtiaque, Shrestha, \& Chhetri, 2017). From a paper published by (Thapa $\&$ Murayama, 2010), it is found that since 2000, the real estate business inside Kathmandu city was not only originated but was found to be boomed which has caused rapid urbanization. In addition to this, the paper also suggests that the influence of the real estate business can be also seen in nearer cities such as bhaktapur,banepa, dhulikhel etc. Thus, due to the attraction of real estate business from Kathmandu, many local people of banepa municipality seems to be found fragmenting their arable land for housing and industrialization to construct modern groceries, restaurants, private parking, etc. which has ultimately created the rapid urbanization inside municipality during 20022020

\section{CONCLUSION}

This study has shown the capability of the latest geospatial technologies such as Geographic Information System (GIS), Remote Sensing (RS), etc. for analyzing urban growth patterns taking the case of Banepa Municipality. It also demonstrates the use of the Analytical Hierarchy Process (AHP) model to analyze the impact of drivers for continuous urban growth from 1992 to 2020 inside Banepa municipality. This study depicts that urbanization in the study area is gradually increasing from 1992 to 2012 and has risen suddenly and cover $18 \%$ of land until coming to 2020. Analytical Hierarchy Process (AHP) was adopted to analyze the impact of drivers which reveals that, Internal migration (57\%) is major drivers for change in urban dynamics whereas, commercialization (25\%), population density (16\%), and real estate business $(5 \%)$ are other respective drivers for alteration of urban land inside the municipality. In addition, the result obtained from this demonstrates that if this pattern continues, there will be rapid urban growth with a quick loss of agricultural land and other existing natural resources. Hence, to prevent rapid urbanization, the concerned authorities must take initiative for implementing land management related policies like Land Use Policy 2015, Land Use Act 2019.

\section{REFERENCE}

Stefanova, W. L., \& Ramseyc, M. S. (2001, March 1). Monitoring urban land cover change:An expert system approach to land cover classification of semiarid to arid urban centers. Remote Sensing of Environment.

Bakrania, S. (2015, 10 29). Urbanization and Urban Growth in Nepal. GSDRC.

Banepa Municipality. (n.d.). Retrieved from Banepa Municipality: https:// banepamun.gov.np/ne/node/3

Devkota, K. (2018). Challenges of Inclusive Urbanization in the Face of Political Transition in Nepal. In J. Mugambwa, \& M. W. Katusiimeh, Handbook of Research on Urban Governance and Managemnet in the Developing World. IGI GLOBAL.

Eddin, B. (n.d.). The Application of Remote Sensing and GIS in Urban Planning.

Ishtiaque, A., Shrestha, M., \& Chhetri, N. (2017, 10 8). Rapid Urban Growth in the Kathmandu Valley,. MDPI.

Joshua, M., \& Katusiimeh, M. (n.d.). Urban Governance and Management in the Developing World. IGI GLOBAL .

Karna, K. B., Shrestha, S., Sainju, S., Sigdel, G. P., Shrestha, S., \& Karmacharya, A. (n.d.). Introduction to Remote Sensing: An Introductory Book. Land Management Training Center, Government of Nepal .

Ministry of Federal Affairs and General Administration. (2017). MOFAGA. Retrieved from https://www.sthaniya. gov.np/gis/ 
Muzzini, E., \& Aparicio, G. (2013). Urban Growth and Spatial Transition in Nepal. The World Bank.

Neill, A. (2021, March 31). Urbanization in Nepal 2019. Statista.

Nepal Urban Population 1960-2021. (2021). Retrieved from Macrotrends: https://www.macrotrends.net/ countries/NPL/nepal/urbanpopulation\#: : text $=$ Nepa $1 \% 20$ urban $\% 20$ population $\% 20$ for $\% 20$ $2019, \mathrm{a} \% 203 \% 25 \% 20$ increase $\% 20$ from $\% 202015$

Rinkesh. (2019). Cause, Effects and Solution of Urbanization. Retrieved from https:// www.conserve-energy-future.com/ causes-effects-solutions-urbanization. php
Saaty, R. (1986). The analytic Hierarchy Process -What it is and How it is used. Mathematical Modelling of Socio Economic Plant Sciences, 20.

Salas, R. M. (1986). Urban Population Dynamics. Asia-Pacific Population Journal, 1(1).

Schlapfer, D., Hueni, A., \& Richter, R. (2018 , Januray 29). Cast Shadow Detection to Quantify the aerosol optical thickess for atmospheric correction of high spatia resolution optical Imagery. Remote Sensing . doi:10.3390/ rs 10020200

Thapa, R. B., \& Murayama, Y. (2010). Drivers of Urban Growth of Kathmandu Valley,Nepal:Examining the Efficacy of the Analytical Hierarchy Process. Applied Geography.

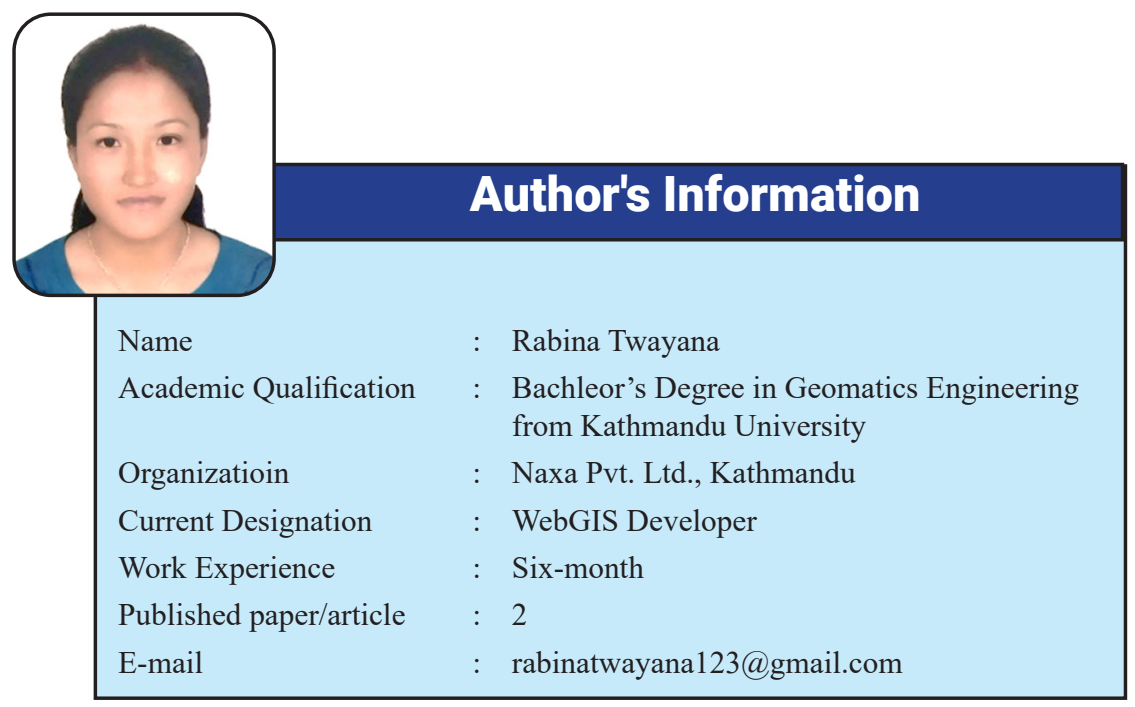

